\title{
Application of Workflow Management Model in Digital Factory
}

\author{
Liu Yong Xi \\ China Aviation Planning And Design Institute Co Ltd, Bei Jing, China \\ yongyi@163.com
}

Keywords: Digital Factory; Workflow Model; Product Lifecycle.

\begin{abstract}
Digital factory is based on the data of product life cycle, and according to the principle of virtual manufacturing and lean production, taking the advantage of computer simulation technology, virtual reality technology and network technology, to carry out three-dimensional simulation, analysis and optimization on the entire production activities, including product design, process planning, logistics planning, comprehensive evaluation and practical application. In this paper, we establish the workflow management model for digital factory, to clearly describes the time factor in all aspects of the business processes, so that comprehensively control the waste of time in workflow.
\end{abstract}

\section{Introduction}

Digital chemical plant is the further development of enterprise information, digital and network technology, which combines simulation technology and virtual reality technology, and realize the real virtual enterprise, so the concept of digital factory is closely linked with virtual manufacturing. Digital factory is a complete model, method and tool, providing support for factory planning and factory operation based on related digital models, including respective operation process.

Generalized digital factory is for the supply chain level, and generally takes manufacturing enterprises as the core, so it is a kind of digital dynamic organization composed of enterprises and their supply chain partners. Generalized digital factory is trying to include all the activities and processes involved in the product. In generalized digital factory system, the entire digital factory system forms the actual business alliance virtual mapping, and generates a massive, agile, virtual network manufacturing system.

Narrow-sense digital factory is further refinement of virtual manufacturing of digital factory core business. Different virtual manufacturing systems are focused on different aspects of the manufacturing process, but they all take computer modeling and simulation technology as an important means of achieving. However, compared with virtual manufacturing, Narrow-sense digital factory is more focused on production planning.

\section{Overall Framework of Digital Factory}

The reason why digital factory can shorten the production cycle and reduce unnecessary waste is that it could realize the digitizing of various links, including product design, manufacturing processes and virtual production, etc. Therefore, implementation process of digital factory covers the process of production systems planning, product development and manufacturing, plans and operational process optimization in production process of manufacturing enterprise.

Digital Factory is originated from enterprise product design, and we divide the implementation process of digital factory into five stages: product design, process planning, logistics planning, comprehensive evaluation and practical application, as shown in Fig. 1: 


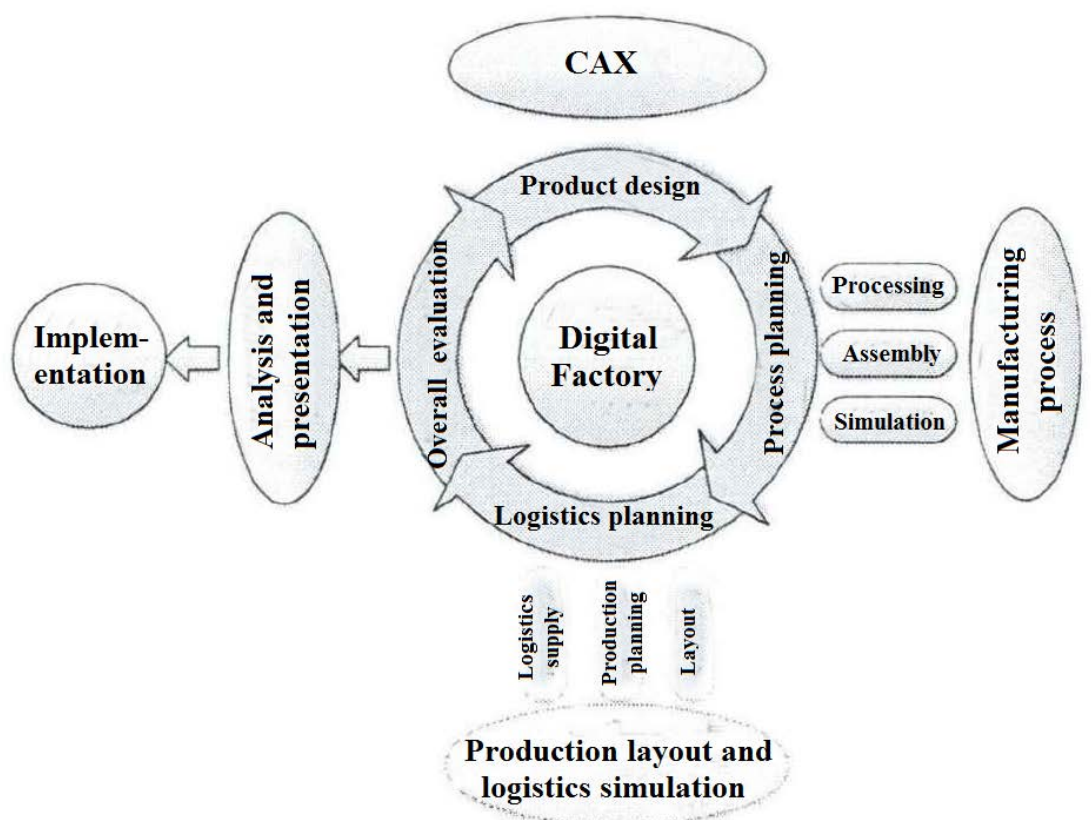

Fig. 1. Implementation process of digital factory

\section{Digital Factory Workflow Process Modeling}

Although there are many scholars dedicated to the study of workflow technology in digital factory, most of them mainly focus on the construction of workflow technology and its implementation, but there is still a lack of research on the modeling method of workflow process in digital factory. On the basis of the present research situation, through the improvement of common workflow process modeling methods, we adopt extended time-based workflow modeling methods to clearly describes the time factor in all aspects of the business processes, so that comprehensively control the waste of time in workflow.

With the continuous improvement of information technology, product production cycle is rapidly shortened, which requires that the business process more streamlined and more refined. To optimize the unnecessary waste of time in business process, it is an inevitable path to reduce production cycle, shorten product delivery cycle and respond quickly to market demand. Therefore, In order to understand the objects and their needs, the most crucial task is to create an object model, and carry out optimization based on analysis of the model.

Model Architectural Structure. In some senses, the factory is a part of the enterprise, and its core business is responsible for the production and processing of manufacturing inspection work. For digital factory, we adopt integrated enterprise model as the reference model. Digital factory model describes the digital factory from three dimensions: view dimension, lifecycle dimension and universal hierarchy dimension.

View Dimension. View dimension is in connection with each link of lifecycle dimension, to conduct modeling and analysis from the six perspectives of process, function, information, products, resources and organization, as shown in Fig. ?: 


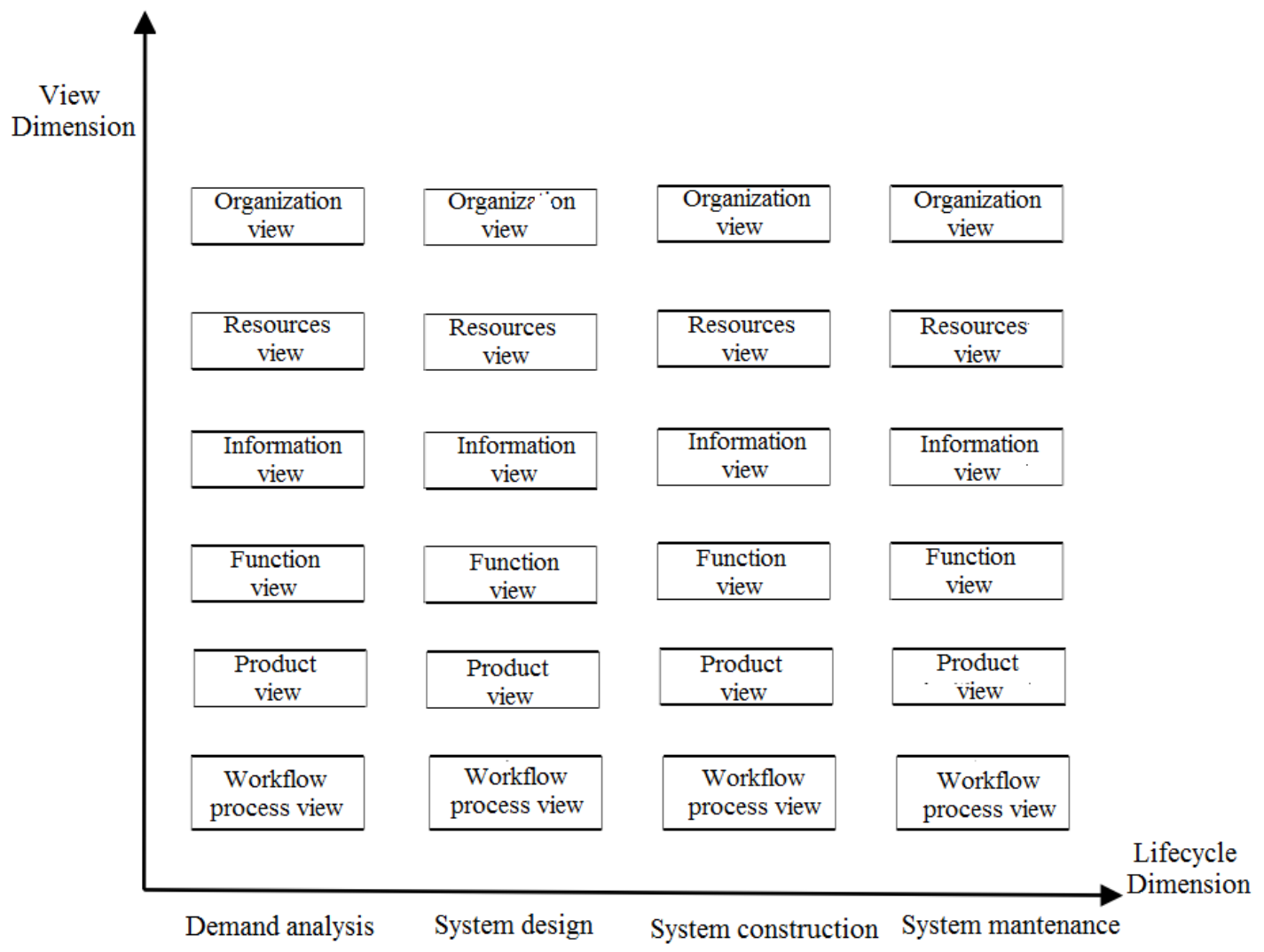

Fig. 2. Relation between view dimension and lifecycle dimension

Workflow view dimension of digital factory is comprised of workflow process view, resources view, organization view, function view, information view and product view. Every view reflects a lateral characteristic and behavior of enterprise, and it can be expressed with a specific model.

Workflow process view is to describe the work flow of digital factory by defining the logical relationship between activities and activities in the digital factory. Modeling of process view can accurately reflect the operation process of the digital factory, including factory management, design, manufacturing processes and factory design, manufacturing optimization process.

Resources view is the definition of the logical relationship between factory resources and their specific properties, as well as resource structure.

Organization view is the definition of organization form of workers, and describes the association between the objects of the organization in factory, as well as specific attributes of employees.

Function view mainly describes the functions of the digital factory, and illustrates the job or task to be done. In addition, it is responsible for the decomposition and interpretation of business goals, and determination of logical structure and relationship of business functions.

Information view describes the information contained in the business object, that is, the input data, output data and the logical relationship between these data when perform specific functional activities. Information views are is the basis of the digital factory to establish reliable business data structure and then generate business database.

Product view is the definition of product structure in factory, and describes the product attributes in various stages and product evolution process.

As shown in Fig. ?, with traditional workflow model, we can extract the process model in the integrated enterprise model, and put it into practice by configuring the corresponding business properties, rules, and time constraints, etc. In this paper, with workflow process model, integrated product, resource, organization, function and information model, we build the workflow view of unified expression, so that reduce the loss of the business because of constant conversion of model and information loss. 


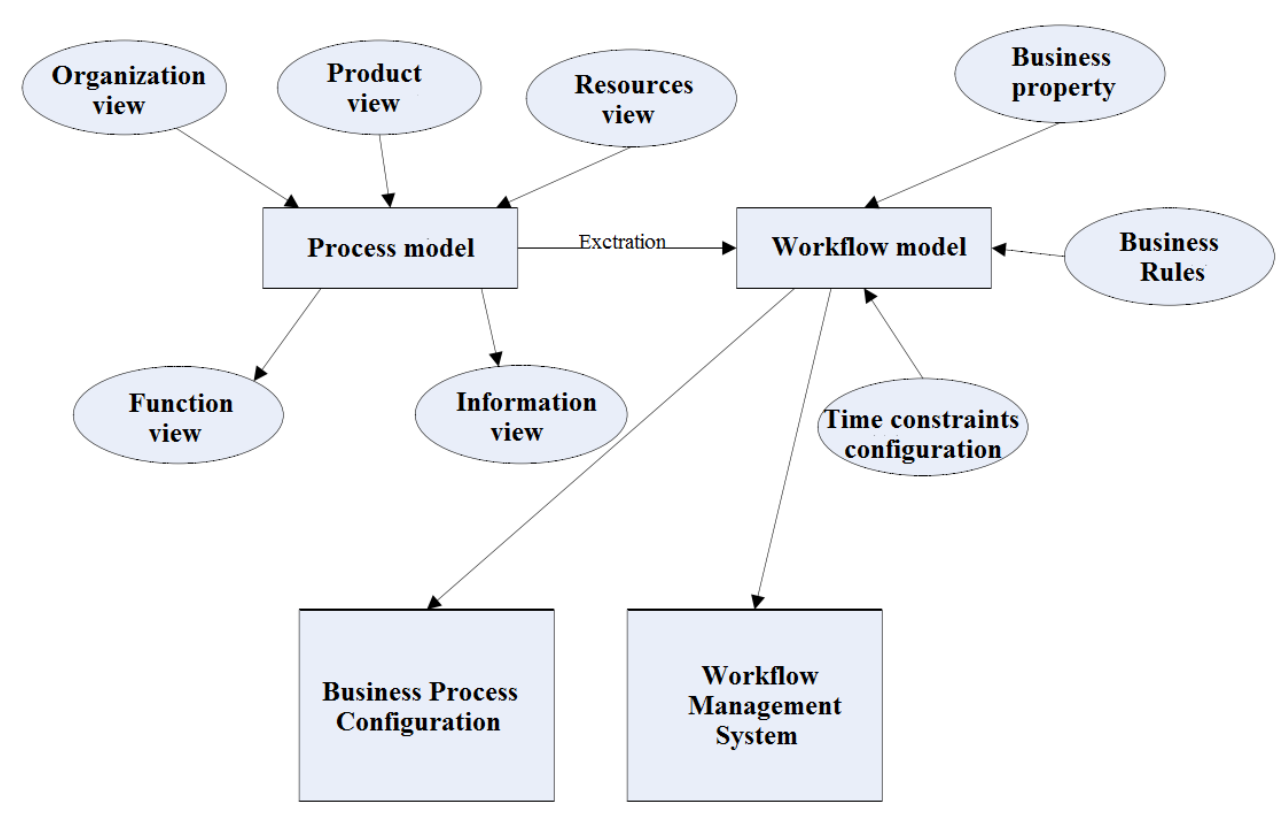

Fig. 3. Transformation of traditional workflow model

Lifecycle Dimension. Both the enterprise and its sub factory have a certain life cycle. It maintains continuous progress and development through a certain life cycle, so its corresponding model also follows this process to evolve.

Lifecycle dimension is also called the time dimension of digital factory, which describes the four stages of digital factory, including requirement analysis, system design, system construction and system implementation. The output of each phase is the input of next stage, and such continuous cycle process also reflects the process of continuous improvement and expansion of the digital factory.

The four stages of the life cycle are closely linked, but they all have their own priorities.

The key point of the demand analysis stage is to establish the demand analysis model. It focuses on business goals, and the essential functions and business process to achieve the goals.

System design stage is based on the demand model, and gradually establishes specific implementation language and implementation methods, and the design model that can be identified by computer. In this stage, process model is the focus, because it can simulate and optimize the business process in the factory.

System construction stage is based on the system design model, and is responsible for gradual planning and layout of the required hardware and software facilities for digital factory. This stage mainly focuses on organization model and resources model, and by the implementation of the optimization method, to improve the efficiency of the plant resources and reduce the cost of the use of resources.

System maintenance stage is mainly for the maintenance of the system to run. Through various document management, version control and other methods, achieve effective management and monitoring of the system. This stage mainly focuses on the use of the control model, making the whole system can run in an orderly way, and timely response to market demand and get updated.

Universal Hierarchy Dimension. Universal hierarchy dimension is also the space dimension of the factory modeling architecture or integrated enterprise. Compared to view dimension, universal hierarchy dimension can be viewed as a lateral structure, which is divided into universal model layer, reference model layer and application model layer. Universal model layer provides basic constituents for the entire integrated digital factory, not only including the basic model component required by different modeling stages and different modeling views, but also including some modeling-related contents such as constraints, terminology, rules, protocols, services, etc. Reference model layer is based on universal model layer, through the analysis and extraction of the typical business process and the behavior of the enterprise, to generate various forms of reference models. 
Application model layer refers to select the appropriate reference model according to the actual situation and needs of the enterprise, and make the appropriate changes to the reference model, so that form specific business model.

Integrated enterprise modeling method is also suitable for the digital factory modeling. Integrated enterprise modeling method takes the establishment and maintenance of a reference model very seriously, because the reference model is established from the research on application case of a large number of projects. They can provide the model framework of practical value for modeling and analysis of business management activities, product design activities and product manufacturing processes in each stage of enterprise information engineering, and help enterprises diagnose, optimize and improve the quality of enterprise modeling, so that reduce the cost of enterprise modeling.

\section{References}

[1] Bylinsky G, Moore A H. the digital factory. Fortune, 1994, 130(10):325-333.

[2] D. Chen. The Digital Factory and Digital Manufacturing - A Review and Discussion. Engineering \& Technology Mechanical Engineering Production Engineering Human Work Science \& Ergonomics, 2009.

[3] W. Cao, Y. Hou, H.E. Qichang, et al. Research on Workshop Layout Planning Based on Digital Factory. Machine Tool \& Hydraulics, 2012.

[4] Yun-Feng W U, Qiu H, Hua-Qiang H U. The Digital Factory Platform Oriented to Design and Manufacture. Manufacture Information Engineering of China, 2011.

[5] Himmler F. The Digital Factory: A Reference Process Based Software Market Analysis. International Journal of Distributed Systems \& Technologies, 2014, 5.

[6] H.P. Yang, E. Lee, S.H. Jeong, et al. Construction and Application of a Digital Factory for Automotive Paint Shops. Frontiers of Assembly \& Manufacturing, 2010. 